\title{
LOW-CARBON CEMENT WITH WASTE OIL-CRACKING CATALYST INCORPORATION
}

\author{
By: \\ Carla Costa \\ Área Departamental Engenharia Civil \\ Instituto Superior de Engenharia de Lisboa \\ Rua Conselheiro Emídio Navarro 1, \\ 1959-007 Lisboa, Portugal \\ Paulo Marques \\ Member, IEEE \\ Instituto de Telecomunicações/Instituto Superior de Engenharia de Lisboa \\ Av. Rovisco Pais 1, 1049-001 Lisboa /Rua Conselheiro Emídio Navarro 1, \\ 1959-007 Lisboa, Portugal
}

\begin{abstract}
The present paper shows preliminary results of an ongoing project which one of the goals is to investigate the viability of using waste FCC catalyst (wFCC), originated from Portuguese oil refinery, to produce low carbon blended cements. For this purpose, four blended cements were produced by substituting cement CEM I $42.5 \mathrm{R}$ up to $20 \%$ (w/w) by waste FCC catalyst. Initial and final setting times, consistency of standard paste, soundness and compressive strengths after 2, 7 and 28 days were measured. It was observed that the wFCC blended cements developed similar strength, at 28 days, compared to the reference cement, CEM I 42.5R. Moreover, cements with waste FCC catalyst incorporation up to 15\% w/w meet European Standard EN 197-1 specifications for CEM II/A type cement, in the 42.5R strength class.
\end{abstract}

Index Terms - Blended cements, Cement industry, Low carbon cement, Pozzolanic material, Sustainability, Waste materials, Waste oil-cracking catalyst.

\section{INTRODUCTION}

The cement industry is responsible for around five per cent of global anthropogenic carbon dioxide $\left(\mathrm{CO}_{2}\right)$ emissions [1], which need to be decreased for environmental reasons. Contribution for this objective has, actually, become a critical issue for the industry. These $\mathrm{CO}_{2}$ emissions come mainly from the combustion of fossil fuels and the decarbonization of limestone during clinker (an intermediate product in cement manufacturing) production step. Therefore, a possible lever to reduce the aforementioned environmental impact of cement industry is the partial substitution of clinker by other materials with cementitious properties [2] producing blended cements. Moreover, if the clinker substitute used is a waste from other industry, this lever also diverts the materials from being disposed in landfills besides increasing the financial profits by turning a polluting waste into a value-added by-product.

European standard EN 197-1 [3] defines, and provides, the composition, specifications and conformity criteria for common cements products and their constituents. This standard is contributing to a substantial reduction of clinker content in cement because it allows the production of blended cement types comprising other main constituents in addition to clinker. The other main constituents may be either 
natural resources (such as limestone, natural pozzolan and shale) or wastes recycle from other industries (such as blast furnace slag, silica fume and fly ash). Standard designations of these cements are: CEM I for cements that main constituent is only clinker and CEM II to CEM V for blended cements with others(s) main constituent(s) besides clinker. Fig. 1 gives a survey of the European deliveries classified by common cement types. CEM I cements are increasingly being replaced by blended cement types (CEM II to CEM V) [4].

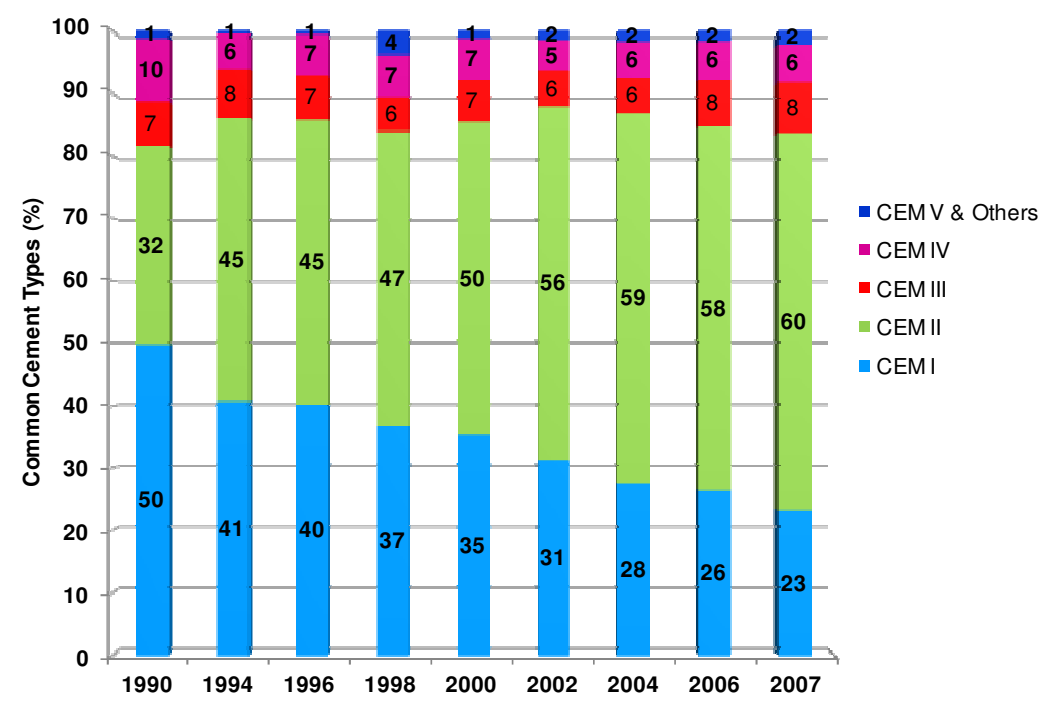

Fig. 1. European deliveries (in \%) classified by common cement types (according to the European Standard EN 197-1) [4]

The uncertainty about the future availability of the established clinker substitutes as well as environmental, technical and economical reasons has been promoting the realization of research studies fostering the identification of other clinker substitutes able to comply with cement standards and performance targets. Within this scope, the possibility of using waste oil-cracking catalyst - originated by the fluid catalytic cracking (wFCC) unit by the Portuguese refinery company - as a clinker substitute is under investigation.

The most active phase of the waste FCC catalysts is zeolite-Y, an aluminosilicate with a crystalline structure consisting of tunnels and cages, which produces a high (internal and external) surface area. The exact composition of these catalysts depends on the manufacturer and on the process that is going to be used. When incorporated in cement-based materials, the wFCC catalyst will be in contact with the cement-water mixture and can undergo a pozzolanic reaction with calcium hydroxide $\left(\mathrm{Ca}(\mathrm{OH})_{2}\right)$ liberated during cement hydration. This reaction produces cement-like hydrated products responsible for the development of mechanical strength.

The pozzolanic reactivity was evaluated measuring the reduction of $\mathrm{Ca}(\mathrm{OH})_{2}$ present in the cement matrix by thermal analysis [5]-[9] and qualitatively by X-ray diffraction, where it was observed that simultaneously to the amount of $\left(\mathrm{Ca}(\mathrm{OH})_{2}\right)$ depletion there is a slightly increase in $\mathrm{C}-\mathrm{S}-\mathrm{H}$ content with the increase of the waste FCC catalyst [10]-[12].

Several researchers have shown that the replacement of cement by FCC catalysts up to $15-20$ wt\% in mortars enhances their early and long term compressive strength [6], [10], [13], [14]. This tendency is not seen for higher percentages probably because: 1) the cement specimens become less workable and therefore have higher porosity and 2) there is less free calcium hydroxide available from the hydration of 
calcium silicates due to a decrease of the cement weight fraction. It has also been shown that the strength of the cement-based materials is markedly enhanced for smaller grain sized catalysts [5], [9], [15]. In terms of durability, it has also been shown that up to $10 \%$ of cement replacement by FCC catalysts there is no additional contribution for the degradation of the cement based materials [16], [17].

Despite the huge benefits of incorporating waste FCC catalysts into cement-based materials, there still remains an extensive lack of fundamental understanding about the reaction mechanisms between the catalyst and the hydration products from the cement material. The project we are carrying out aims to address these issues and to foster the development of these blended cement materials, such as which large-scale industrial applications can be achieved in the future. Preliminarily results from a series of tests conducted on cement type CEM I 42,5 R incorporating 5 to $20 \% \mathrm{w} / \mathrm{w}$ of waste FCC catalyst shows that blended cements with waste FCC catalyst incorporation up to $15 \% \mathrm{w} / \mathrm{w}$ complies with the specifications set out in EN 197-1 for CEM II/A, in the 42.5R strength class.

\section{EXPERIMENTAL PROGRAM}

\section{A. Materials}

The cement used was a commercial portland cement CEM I 42,5 R (according to European standard EN 197-1 [3]). The waste oil-cracking catalyst used is originated by the fluid catalytic cracking (FCC) unit in a portuguese refinery plant.

The chemical composition of these materials was obtained by $X$-ray fluorescence spectrometry. The loss on ignition and chloride content were evaluated following European Standards EN 196-2 and EN 196-21 [19], respectively. Chemical composition is listed in Table I. The wFCC consists of basically $\mathrm{SiO}_{2}$ and $\mathrm{Al}_{2} \mathrm{O}_{3}$, representing approximately $92 \% \mathrm{w} / \mathrm{w}$, with minor contents of $\mathrm{Ti}_{2} \mathrm{O}_{3}, \mathrm{Na}_{2} \mathrm{O}, \mathrm{Fe}_{2} \mathrm{O}_{3}, \mathrm{SO}_{3}, \mathrm{MgO}, \mathrm{CaO}$, $\mathrm{P}_{2} \mathrm{O}_{5}$ and $\mathrm{K}_{2} \mathrm{O}$. This chemical composition is typical of some other pozzolanic materials used in the cement industry.

TABLE I

CHEMICAL COMPOSITION AND PHYSICAL CHARACTERISTICS OF THE CEMENT AND WFCC USED

\begin{tabular}{|c|c|c|}
\hline \multirow[t]{2}{*}{ Compound } & \multicolumn{2}{|c|}{ Chemical analysis (\% w/w) } \\
\hline & Cement & wFCC \\
\hline $\mathrm{SiO}_{2}$ & 19.41 & 39.59 \\
\hline $\mathrm{Al}_{2} \mathrm{O}_{3}$ & 5.45 & 52.81 \\
\hline $\mathrm{Fe}_{2} \mathrm{O}_{3}$ & 3.23 & 0.55 \\
\hline $\mathrm{CaO}$ & 62.57 & 0.09 \\
\hline $\mathrm{MgO}$ & 1.91 & 0.19 \\
\hline $\mathrm{SO}_{3}$ & 2.89 & 0.23 \\
\hline $\mathrm{K}_{2} \mathrm{O}$ & 1.10 & 0.04 \\
\hline $\mathrm{Na}_{2} \mathrm{O}$ & 0.00 & 0.68 \\
\hline $\mathrm{Ti}_{2} \mathrm{O}_{3}$ & 0.27 & 0.82 \\
\hline $\mathrm{P}_{2} \mathrm{O}_{5}$ & 0.10 & 0.06 \\
\hline $\mathrm{Mn}_{2} \mathrm{O}$ & 0.05 & 0.00 \\
\hline SrO & 0.07 & 0.00 \\
\hline Cl- & 0.02 & 0.01 \\
\hline Loss by ignition & 2.70 & 1.49 \\
\hline
\end{tabular}

The particle size distributions (PSD) of the cement and waste FCC catalyst were obtained by laser 
diffraction (Fig. 2). The $d_{50}$ and $d_{90}$ are the values of particles sizes below which $50 \%$ and $90 \%$, respectively, of the total volume, are situated. The $d_{50}$ of cement and wFCC particles are $21.5 \mu \mathrm{m}$ and $80.0 \mu \mathrm{m}$, respectively and the $d_{90}$ of cement and wFCC particles are $56.0 \mu \mathrm{m}$ and $124.3 \mu \mathrm{m}$, respectively.

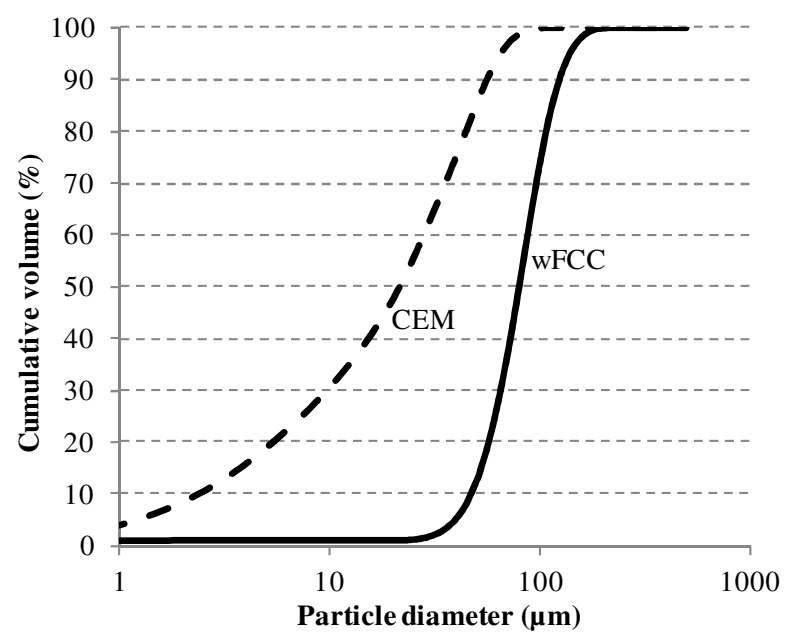

Fig. 2. Cumulative volume particle size distributions of cement CEM I $42.5 R$ and waste FCC catalyst (wFCC)

The natural siliceous sand used was conforming to European standard EN 196-1 [21]. SIKAPlast 898 superplasticizer $(\mathrm{Sp})$ and deionised water were used in mortar preparation.

\section{B. Methods to study the blended cements with waste FCC catalyst incorporation}

Blended cements were formulated by partially replacing cement CEM I $42.5 \mathrm{R}$ with wFCC catalyst within the range of 5 to $20 \%(\mathrm{w} / \mathrm{w})$ with an increment of $5 \%$. Notation adopted for the cements is summarised in Table II.

TABLE II

NOTATION ADOPTED FOR CEMENTS USED

\begin{tabular}{llll}
\hline \multirow{2}{*}{ Cements Notation } & \multicolumn{2}{l}{ Mixture proportions (\% w/w) } \\
\cline { 3 - 4 } & & Cement 42.5 R & wFCC \\
\hline Reference & C100 & 100 & 0 \\
\hline \multirow{4}{*}{ Composite } & C95_wFCC5 & 95 & 5 \\
cements & C90_wFCC10 & 90 & 10 \\
& C85_wFCC15 & 85 & 15 \\
& C80_wFCC20 & 80 & 20 \\
\hline
\end{tabular}

The standard consistency, the initial and final setting times and the soundness of the cement pastes were determined following European Standard EN 196-3 [22].

Cement mortars were prepared using water, sand, binder and superplasticizer, in a weight ratio $(\mathrm{w} / \mathrm{s} / \mathrm{b} / \mathrm{Sp}$ ) of $0.5 / 3 / 1 / 0.005$, respectively. Mortars mixing procedure was performed in accordance with European Standard EN 196-1, excepted in previous mixture of the superplasticizer in the water [21]. 
Consistency of fresh mortars was evaluated, immediately after mixing, by flow table test as prescribed in European Standard EN 1015-3 [23]. After the flow test, mortars were placed in prismatic steel moulds and cured so that compressive strengths were able to be evaluated at 2, 7 and 28 days of ages in accordance with European Standard EN 196-1 [21].

\section{RESULTS AND DISCUSSION}

The water requirement to prepare cement pastes of standard consistency, their initial and final setting times, determined by Vicat probe and Vicat needle apparatus, as well as the results of soundness (expansion according to Le Chatelier process) are reported in Table III.

TABLE III

PHYSICAL PROPERTIES OF THE COMPOSITE CEMENTS WITH WASTE FCC CATALYST INCORPORATION

\begin{tabular}{|c|c|c|c|c|}
\hline \multirow[t]{2}{*}{ Cement } & \multirow{2}{*}{$\begin{array}{l}\text { Water demand for } \\
\text { standard consistency } \\
(\% \mathrm{w} / \mathrm{w})\end{array}$} & \multicolumn{2}{|c|}{ Setting time (min) } & \multirow{2}{*}{$\begin{array}{l}\text { Le Chatelier } \\
\text { expansion } \\
(\mathrm{mm})\end{array}$} \\
\hline & & Initial & Final & \\
\hline C100 & 24.2 & 310 & 345 & 0 \\
\hline C95_wFCC5 & 25.6 & 300 & 355 & 1 \\
\hline C90_wFCC10 & 27.2 & 260 & 310 & 1 \\
\hline C85_wFCC15 & 28.6 & 240 & 300 & 1 \\
\hline C90_wFCC20 & 30.0 & 220 & 255 & 0 \\
\hline
\end{tabular}

As shown in Table III, the water required in order to prepare cement pastes with standard consistency (as specified in EN 196-3 [22]) increases linearly with the waste FCC catalyst ratio in cement. This behaviour is attributed to the microporous structure and high surface area with high water affinity of the FCC catalyst. On the other hand, cements with waste FCC catalyst incorporation have, typically, slightly shorter initial and final setting times than the reference cement pastes and these times decrease by increasing the waste catalyst ratio in the cement. The only exception is for C95_wFCC5 cement which shows a final setting time slightly longer than the pure cement paste. More work has to be done to establish whether the faster hydration of cement in the presence of FCC catalyst is due to its chemical reactivity upon dissolution (pozzolanic activity) or to a high surface activity. The expansion measured for some cements with waste FCC catalyst incorporation is not significant.

The spread values on flow table test (Fig. 3) are also affected by waste FCC catalyst ratio incorporation in cement. By increasing the waste FCC catalyst content there is a linear reduction in the spread value obtained on flow table and therefore in the mortar fluidity. The trend of these results are in good agreement with the water demand required for the preparation of cement pastes with standard consistency (Table III) and, as previously mentioned, should also be attributed to the high water absorption ability presented be the waste FCC catalyst. 


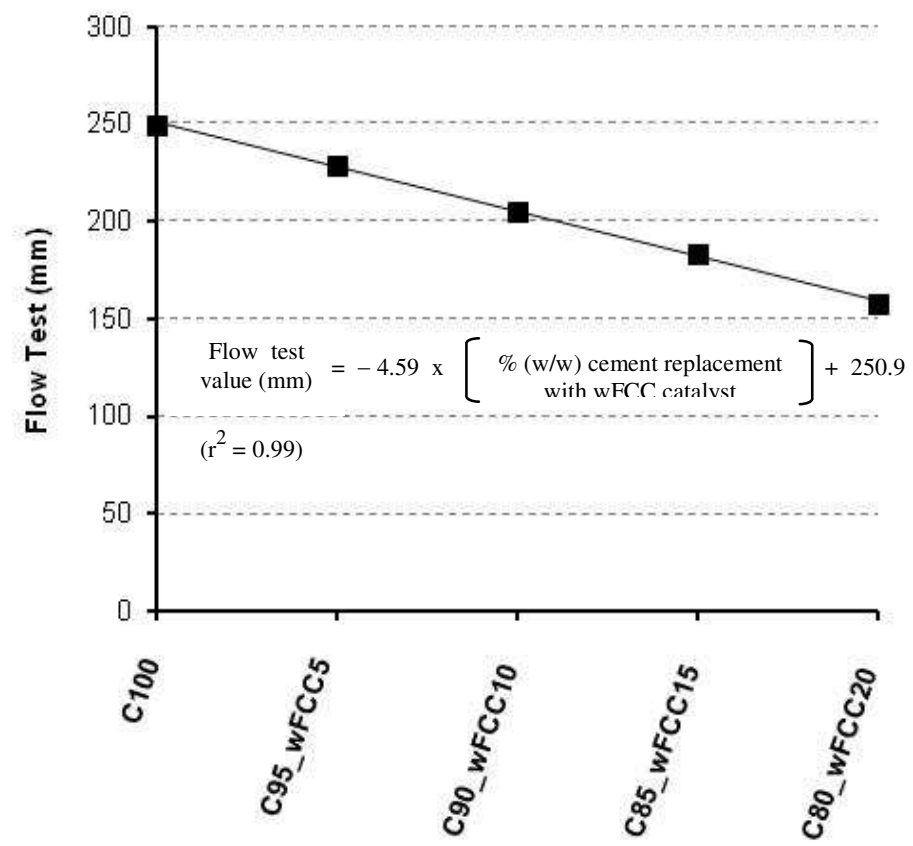

Fig. 3. Spread values on flow table test of mortars with $0,5,10$, 15 and $20 \%$ (w/w) of cement replacement with wFCC catalyst

Fig. 4 shows the compressive strength of the mortars with $0,5,10,15$ and $20 \% \mathrm{w} / \mathrm{w}$ of cement replacement with wFCC catalyst for different curing ages.

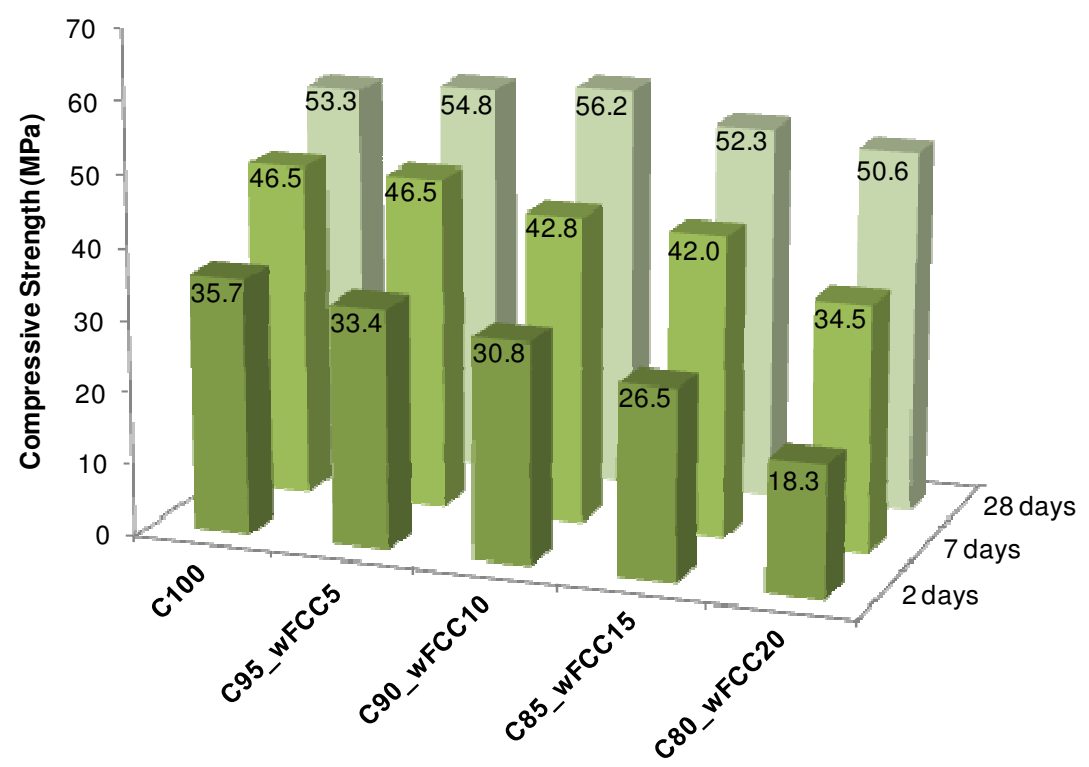

Fig. 4. Compressive strength of mortars with 0, 5, 10, 15 and $20 \%$ (w/w) of cement replacement with wFCC catalyst for 2, 7 and 28 days of age

Results presented in Fig. 4 show that on the 7th day of hydration, cements with waste FCC catalyst incorporation up to $10 \% \mathrm{w} / \mathrm{w}$ exhibit already strength-enhanced slightly higher than that of the relative pure cement. The addition of 15 and $20 \% \mathrm{w} / \mathrm{w}$ of waste FCC catalyst delay the strength development during the first 28 days of hydration but from this curing age the strength is similar with that of the cement 
without waste incorporation.

Among a wide range of test methods for assessing pozzolanic activity [24], [25] one that has been widely used consists in determining the Strength Activity Index (SAI). According to American standard ASTM C311 [26], SAl is defined as the ratio (in \%) between the compressive strength of mortar produced with $20 \%(\mathrm{w} / \mathrm{w})$ of cement replacement by the test pozzolan material and the compressive strength of reference mortar (without pozzolan incorporation) at the same ages, at the end of the curing time of 7 and 28 days.

In this work, an extrapolation of this calculation has been considered for each percentage of cement replacement by the wFCC catalyst and for each curing age. Therefore, SAI value was computed as the ratio (in \%) of the average compressive strength of the mortars test specimens produced with a certain percentage of cement replacement by wFCC catalyst and the average compressive strength of reference mortars test specimens, at the same age, produced in exactly the same conditions (Table IV).

TABLEIV

STRENGTH ACTIVITY INDEX VALUES (IN \%) FOR MORTARS PRODUCED WITH 0, 5, 10, 15 AND 20\% (W/W) WFCC CATALYST INCORPORATION AT 2, 7 AND 28 DAYS OF AGE

\begin{tabular}{|c|c|c|c|c|c|}
\hline \multirow{2}{*}{$\begin{array}{l}\text { Age } \\
\text { (days) } \\
\end{array}$} & \multicolumn{5}{|l|}{ Cements } \\
\hline & C100 & $\mathrm{C} 95$ & wFCC5 C90 & wFCC10 C85 & wFCC15 C80_wFCC20 \\
\hline 2 & 100 & 94 & 86 & 74 & 51 \\
\hline 7 & 100 & 100 & 92 & 90 & 74 \\
\hline 28 & 100 & 103 & 105 & 98 & 95 \\
\hline
\end{tabular}

Incorporation of pozzolanic materials in mortars affects strength development and, therefore, SAI values, due the following three effects [27]: dilution effect, physical effect and pozzolanic activity. Dilution effect is a consequence of the partial replacement of cement by other material, which should lead to a decrease in compressive strength of the mortar proportional to the amount of cement replacement. Physical effects are mainly attributed to the addition particles filling ability associated to their deposition in the intergranular voids between cement particles, which leads to a denser cement mortar matrix and, therefore, to the mechanical properties improvement. Pozzolanic effect also promotes an increase in the mechanical properties related to the occurrence of the pozzolanic reaction which forms additional strength-providing reaction products i.e., C-S-H and C-A-H.

Since FCC catalyst particles are coarser than the cement particles, their filling ability in the waste FCC catalyst blended cement mortars produced is not expected to be significant. This implies that physical effect of waste FCC catalyst particles on strength compression development can be neglected [27]. Therefore, compressive strength increase of mortars with wFCC catalyst incorporation beyond the value expected for their strength, considering the dilution effect, should only be attributed to waste FCC catalyst pozzolanic activity. Results included in Table IV show that FCC catalyst already present relevant pozzolanic activity in cements with catalyst incorporation up to $15 \% \mathrm{w} / \mathrm{w}$, on 7 th day of hydration. Pozzolanity is also evident in cement with $20 \% \mathrm{w} / \mathrm{w}$ of FCC catalyst incorporation, after 28 days of curing age, because SAI value is significantly higher than the expected values if only the dilution effect is considered which should be $80 \%$.

\section{CONCLUSION}

Waste FCC particles exhibit significant pozzolanic activity since cements with waste FCC catalyst incorporation up to $20 \% \mathrm{w} / \mathrm{w}$ exhibit a strength-enhanced which is similar with that of the reference cement, after 28 days of curing age.

Table V presents mechanical, physical and chemical requirements laid down in European Standard 197-1 
[3] for the portland cements with up to $20 \%$ of other main constituent, CEM II/A, in the $42.5 \mathrm{R}$ strength class as well as systematize the correspondent values obtained with the waste FCC catalyst blended cements under study. It can be, therefore, deduced that cements with waste FCC catalyst incorporation up to $15 \% \mathrm{w} / \mathrm{w}$ complies with the specifications set out in EN 197-1 for CEM II/A, in the 42.5R strength class.

TABLE V

REQUIREMENTS LAID DOWN IN EUROPEAN STANDARD 197-1 [3] FOR COMMON CEMENTS, CEM II/A, IN THE 42.5R STRENGTH CLASS AND CORRESPONDENT VALUES OBTAINED WITH THE WASTE FCC CATALYST BLENDED CEMENTS

\begin{tabular}{|c|c|c|c|c|c|}
\hline \multirow[t]{2}{*}{ Properties } & \multirow{2}{*}{$\begin{array}{l}\text { Requirements } \\
\text { EN 197-1 }\end{array}$} & \multicolumn{4}{|l|}{ Results } \\
\hline & & C95_wFCC5 & C90_wFCC10 & C85_wFCC15 & C80_wFCC20 \\
\hline $\begin{array}{l}\text { Early strength, } \\
2 \text { days (MPa) }\end{array}$ & $\geq 20$ & 33.4 & 30.8 & 26.5 & 18.3 \\
\hline $\begin{array}{l}\text { Standard strength, } 28 \\
\text { days (MPa) }\end{array}$ & $\leq 62.5$ & 54.8 & 56.2 & 52.3 & 50.6 \\
\hline $\begin{array}{l}\text { Initial setting time } \\
(\mathrm{min})\end{array}$ & $\geq 60$ & 300 & 260 & 240 & 220 \\
\hline $\begin{array}{l}\text { Soundness expansion } \\
(\mathrm{mm})\end{array}$ & $\leq 10$ & 1 & 1 & 1 & 0 \\
\hline $\begin{array}{l}\mathrm{SO}_{3} \text { content } \\
(\%)\end{array}$ & $\leq 4.0$ & 2.76 & 2.62 & 2.49 & 2.36 \\
\hline $\begin{array}{l}\text { Chloride content } \\
(\%)\end{array}$ & $\leq 0.1$ & 0.02 & 0.02 & 0.02 & 0.02 \\
\hline
\end{tabular}

Therefore, major findings in this investigation revealed that the use of waste FCC catalysts as clinker substitute is feasible, strengthening the belief that this material may represent a steady supply for cement industry making a significant contribution to lower the carbon footprint of the cement industry, being economically interesting both by reducing the landfill usage and by turning an otherwise polluting waste into a value-added by-product.

\section{ACKNOWLEDGMENT}

The authors acknowledge the support of Fundação para a Ciência e Tecnologia (FCT) through project funding PTDC/ECM/113115/2009, to R. Geada for carrying out some of the laboratorial tasks and to J. Pereira for the helpful discussions about some of the results.

\section{REFERENCES}

[1] A. Morbi, S.Cangiano, E. Borgarello, "Cement Based Materials for Sustainable Development", in Proc. Sessions in Honor of: Dr. Enrico Borgarello, Professor Theodore W. Bremner, Professor David W. Fowler, Professor Konstantin Kovler, Professor Koji Sakai. Milwaukee: UWM Center for By-Products Utilization (Zachar J, Claisse P, Naik TR, Ganjian E, editors), pp. 1-10, June 2010.

[2] World Business Council for Sustainable Development (WBCSD)/ International Energy Agency (IEA), "Cement Technology Roadmap 2009, Carbon emissions reductions up to 2050", 2009 [Online] Available: http://www.iea.org/papers/2009/Cement_Roadmap.pdf

[3] European Standard EN 197-1:2000, Cement: Part 1. Compositions and conformity criteria for common cements, 89/106/EEC.

[4] Global Cement Report, International Cement Review, 8th Ed., 2009.

[5] B. Pacewska, I. Wilinska, M. Bukowska, W. Nocun-Wczelik, "Effect of waste aluminosilicate material on cement hydration and properties of cement mortars" Cement and Concrete Research, 32 (11) (2002) pp. 1823-1830.

[6] J. Paya, J. Monzo, M. V. Borrachero, S. Velázquez, "Evaluation of the pozzolanic activity of fluid catalytic cracking catalyst residue (FC3R). Thermogravimetric analysis studies on FC3R Portland cement pastes." Cement and Concrete Research, 33(4) (2003) pp. 603-609.

[7] B. Pacewska, I. Wilińska, M. Bukowska, G. Blonkowski, W. Nocuñ-Wczelik, "An attempt to improve the pozzolanic activity of waste aluminosilicate catalyst" Journal of Thermal Analysis and Calorimetry 77(1) (2004) pp. 133-142.

[8] J. Dweck, C. Pinto, P. Büchler, "Study of a Brazilian spent catalyst as cement aggregate by thermal and mechanical analysis", Journal of Thermal Analysis and Calorimetry, 92(1) (2008) pp. 121-127.

[9] A. Cherem da Cunha, M. S. Lemos, S. Meth, J. P. Gonçalves, J. Dweck, "A study of the particle size effect on the pozzolanic activity of an equilibrium catalyst", Journal of Thermal Analysis and Calorimetry, 106 (2011) pp. 805-809. 
[10] J.-H. Wu, W.-L. Wu, K.-C. Hsu, "The effect of waste oil-cracking catalyst on the compressive strength of cement pastes and mortars." Cement and Concrete Research, 33(2) (2003) pp. 245-253.

[11] M. Bukowska, B. Pacewska, I. Wilińska, "Corrosion resistance of cement mortars containing spent catalyst of fluidized bed cracking (FBCC) as an additive", Journal of Thermal Analysis and Calorimetry 74(3) (2003) pp. 931-942.

[12] J. Payá, M.V. Borrachero, J. Monzó, L. Soriano, "Studies on the behaviour of different spent fluidized-bed catalytic cracking catalysts on Portland cement", Materiales de Construcción, 59 (2009) pp. 37-52.

[13] H.-L. Chen, Y.-S. Tseng, K.-C. Hsu, "Spent FCC catalyst as a pozzolanic material for high performance mortars." Cement and Concrete Composites, 26(6) (2004) pp. 657-664.

[14] E. Zornoza, P. Garcés, J. Monzó; M. V. Borrachero, J. Payá, "Compatibility of fluid catalytic cracking catalyst residue (FC3R) with various types of cement", Advances in Cement Research, 19(3) (2007) pp. 117-124

[15] J. Payá, J. Monzó, Borrachero, M. V., "Fluid catalytic cracking catalyst residue (FC3R): An excellent mineral by-product for improving early-strength development of cement mixtures", Cement and Concrete Research, 29(11) (1999) pp. $1773-1779$.

[16] B. Pacewska, M. Bukowska, I. Wilinska, M. Swat, "Modification of the properties of concrete by a new pozzolan--a waste catalyst from the catalytic process in a fluidized bed", Cement and Concrete Research, 32(1) (2002) pp. 145-152.

[17] E. Zornoza, J. Payá, P. Garcés, "Chloride-induced corrosion of steel embedded in mortars containing fly ash and spent cracking catalyst" Corrosion Science, 50(6) (2008) pp. 1567-1575.

[18] E. Zornoza, J. Payá, j. Monzó, M.V. Borrachero, P. Garcés, "The carbonation of OPC mortars partially substituted with spent fluid catalytic catalyst (FC3R) and its influence on theirmechanical properties", Construction and Building Materials, 23(3) (2009) pp. 1323-1328.

[19] European Standard EN 196-2: 2005, Methods of testing cement - Part 2: Chemical analysis of cement, 89/106/EEC.

[20] C. Costa, M. Juenger, P.J. Ferreira, P.A. Carvalho, "Microstructural Analysis of Cement Pastes Blended with Catalysts from Oil Refinery", in Proc. Euromat 2009 - European Congress and Exhibition on Advanced Materials and Proccesses, Glasgow, United Kingdom, Sept. 2009.

[21] European Standard EN 196-1:2005, Methods of testing cement - Part 1: Determination of strength, 89/106/EEC.

[22] European Standard EN 196-3, Methods of testing cement - Part 3: Determination of setting time and soundness, 89/106/EEC.

[23] European Standard EN 1015-3:2007, Methods of test for mortar for masonry: determination of consistence of fresh mortar (by flow table), 89/106/EEC.

[24] Y.-S. Tseng, C.-L. Huang, K-C. Hsu, "The pozzolanic activity of a calcined waste FCC catalyst and its effect on the compressive strength of cementitious materials", Cement and Concrete Research, 35(4) (2005) pp. 782-787.

[25] S. Donatello, M. Tyrer, C. R, Cheeseman, "Comparison of test methods to assess pozzolanic activity", Cement and Concrete Composites, 32(2) (2010) pp. 121-127.

[26] ASTM C311-02, Standard test methods for sampling and testing fly ash or natural pozzolan for use in Portland-cement concrete, Annual Book of ASTM Standards (2002).

[27] M. Cyr, P. Lawrence, E. Ringot, "Efficiency of mineral admixtures in mortars: Quantification of the physical and chemical effects of fine admixtures in relation with compressive strength", Cement and Concrete Research, 36(2) (2006) pp. 264-277. 